\section{Michigan Technological 1885 University}

Michigan Technological University Digital Commons @ Michigan Tech

2-19-2014

\title{
Effects of Spectral Albedo on Solar Photovoltaic Devices
}

M. P. Brennan

Michigan Technological University

A. L. Abrahamse

Universidad Privada Boliviana

Rob W. Andrews

Queen's University - Kingston, Ontario

Joshua M. Pearce

Michigan Technological University

Follow this and additional works at: https://digitalcommons.mtu.edu/materials_fp

\section{Recommended Citation}

M.P. Brennan, A.L. Abramase, R.W. Andrews, J. M. Pearce, Effects of spectral albedo on solar photovoltaic devices, Solar Energy Materials and Solar Cells, 124, pp. 111-116,(2014). http://digitalcommons.mtu.edu/ materials_fp/30/ 
Published: M.P. Brennan, A.L. Abramase, R.W. Andrews, J. M. Pearce, Effects of spectral albedo on solar photovoltaic devices, Solar Energy Materials and Solar Cells, 124, pp. 111-116,(2014). DOI: http://dx.doi.org/10.1016/j.solmat.2014.01.046.

\title{
Effects of spectral albedo on solar photovoltaic devices
}

M. P. Brennan, ${ }^{1}$ A. L. Abramase, ${ }^{2}$, R. W. Andrews ${ }^{3}$, and J. M. Pearce ${ }^{4}$

${ }^{1}$ Department of Physics, Michigan Technological University, Michigan, USA

${ }^{2}$ Department of Physics, Universidad Privada Boliviana, Bolivia

${ }^{3}$ Department of Mechanical and Materials Engineering, Queen's University, Canada

${ }^{4}$ Department of Materials Science \& Engineering and Department of Electrical \& Computer

Engineering, Michigan Technological University, Michigan, USA

*Corresponding author

601 M\&M Building

1400 Townsend Drive

Houghton, MI 49931-1295

906-487-1466

pearce@mtu.edu

\begin{abstract}
Although the spectral effects of direct and diffuse radiation on solar photovoltaic (PV) performance are relatively well understood, recent investigations have shown that there can be a spectral bias introduced due to albedo from common ground surfaces that can impact the optimal selection of PV materials for a known location. This paper extends analysis to the effects of spectral bias due to the specular reflectivity of twenty-two commonly occurring surface materials (both man-made and natural) and analyzes the albedo effects on the performance of seven PV materials covering three common PV system topologies: industrial (solar farms), commercial flat rooftops and residential pitched roof applications. An effective albedo is found for each surface material and PV material combination, which can be used in lieu of broadband albedo values in PV simulations. These results enable PV material selection for specific environments enabling geographic optimization for the microenvironment, while at the same time assisting optimal surface selection in the vicinity of existing or planned PV arrays. This analysis is of particular significance for the modeling of performance of bifacial PV modules and vertical BIPV.
\end{abstract}

Keywords: albedo; reflection; spectral albedo; spectral mismatch factor; photovoltaic; quantum efficiency; spectral response

\section{Introduction}

Given the earth's plentiful solar resource, solar photovoltaic (PV) energy conversion provides the largest potential of any sustainable energy source to mitigate greenhouse gas emissions [1] and the negative environmental [2], health [3], and economic [4] ramifications of anthropogenic climate change [5]. Although photovoltaic systems are becoming economically competitive with conventional fossilfuel sources in an expanding list of geographic regions [6], cost remains a major barrier to abundant energy while remaining within the necessary physical limits of life cycle carbon emissions [7]. PV must grow from the tens of gigawatt-level to the terawatt level to halt the rise of $\mathrm{CO}_{2}$ concentrations in the atmosphere [8,9]. In order to accelerate the diffusion of PV technologies, the electrical output on a per cost basis must be optimized.

One area of PV system optimization that has received relatively modest investigation in the past is the 
Published: M.P. Brennan, A.L. Abramase, R.W. Andrews, J. M. Pearce, Effects of spectral albedo on solar photovoltaic devices, Solar Energy Materials and Solar Cells, 124, pp. 111-116,(2014). DOI: http://dx.doi.org/10.1016/j.solmat.2014.01.046.

effect of spectral albedo on system performance. Different system topologies can result in significant contributions from reflected (albedo) irradiation. For example, systems which have a large tilt angle relative the ground can have a relatively large albedo contribution, especially if the area ahead of the module is unobstructed. Therefore, vertical PV systems (as have been seen in building integrated systems) and to a lesser extent high tilt angle ground mounted PV systems (as are installed at northern latitudes) can both be significantly impacted by albedo irradiation [10]. In addition, bi-facial modules rely heavily on the reflection of irradiation onto the rear plane of the module, which in some cases can be as high as $25 \%$ of incident irradiation on the front of the module [11]. Overall, these systems have been shown to utilize albedo to produce $120 \%$ more energy than a mono-facial unit, and therefore the optimization and modeling of these systems requires high-quality albedo predictions [12].

Albedo irradiation changes the spectral distribution of the incident irradiation on the surface of the PV device, which in turn affects system output. In general, PV modules based on commercial semiconductor materials are optimized under Standard Testing Conditions (STC), which are defined as $1000 \mathrm{~W} / \mathrm{m}^{2}$ irradiance with an AM1.5 spectrum at $25^{\circ} \mathrm{C}$ [13]. This is not always a valid assumption, as there are long-established daily, locational and seasonal shifts in the spectral distribution of incident radiation at ground level [14-17]. Optimizing for STC can lead to modeling errors and sub-optimal system design as it produces an improper spectral weighting, which is used to calculate a PV device's response to irradiance.

In most PV system design tools the spectral distribution of albedo irradiation is ignored, and is assumed to be similar in composition to atmospheric irradiation, leading to the use of a spectrally averaged albedo in many simulations. The spectrally averaged albedo represents the albedo given by the broadband integration of a spectral albedo distribution, and typically for a single atmospheric spectrum [10]. In other words, if the spectrally distributed reflectivity is given by the function $A(\lambda)$, then the percentage of reflected light is generally measured as:

$$
\alpha=\frac{\int G(\lambda) A(\lambda) d \lambda}{\int G(\lambda) d \lambda}
$$

which gives a constant value of albedo that is commonly extended to all spectral conditions. The reflected light $\left(\mathrm{r}_{\mathrm{e}}\right)$ is then estimated by multiplying this constant albedo by the integrated broadband spectrum at this point.

$$
r_{e}=\left(\frac{\int G(\lambda) A(\lambda) d \lambda}{\int G(\lambda) d \lambda}\right) \times\left(\int G(\lambda) d \lambda\right)=\alpha \times E
$$

where $G(\lambda)$ is the broadband spectrum incident on the surface and $E$ is the integrated broadband spectrum. This common formulation ignores the spectral complexity and assumptions made in the measurement of a single spectrally averaged albedo, and a more precise calculation of the reflected light should take into account the spectral variance in both the surface reflectivity and the light incident on the surface.

When taking this into account, it has been seen previously that surface materials can have a significant effect on not only the absolute amount of reflected light, but also in its spectral distribution. As an example, it has been found that snow will tend to bias its reflectivity towards the ultraviolet and "blue" side of the spectrum, whereas grass will tend to reflect preferentially after the "green" portion of the spectrum due to the effects of photosynthesis [10]. 
Published: M.P. Brennan, A.L. Abramase, R.W. Andrews, J. M. Pearce, Effects of spectral albedo on solar photovoltaic devices, Solar Energy Materials and Solar Cells, 124, pp. 111-116,(2014). DOI: http://dx.doi.org/10.1016/j.solmat.2014.01.046.

Given that PV materials have a defined spectral responsivity, these spectral biases can ultimately affect the power output of a PV device differently than would be assumed for a constant broadband albedo. This spectral biasing due to the surface reflectivity of common ground surfaces (snow and grass) has been shown to have a significant impact on PV output, depending on the type of PV material analyzed. Thus, it has been seen that consideration of the spectral contribution of the albedo is critical to the proper modeling of PV systems [10].

This paper extends the preliminary analysis in [10] to the effects of spectral biasing due to the albedo of a range of twenty-two environmental surface materials, and their effects on the performance of three common system topologies: industrial, commercial and residential. This analysis will enable PV material selection for specific environments enabling geographic optimization for the microenvironment, while at the same time assisting optimal surface selection in the vicinity of existing or planned PV arrays.

\section{Methodology}

\subsection{Calculation of spectral effects on module performance}

In this study, the short circuit current (Isc) will be utilized as a proxy for panel performance. This study is primarily interested in defining the changes in effective irradiance on the surface of a module, which can be modeled accurately by considering only the $\mathrm{I}_{\mathrm{sc}}$. Implicit in this assumption is that the effects of increased module temperature due to thermalization and efficiency losses, which could effect the voltage of the system are ignored.

The $\mathrm{I}_{\mathrm{sc}}$ output of a PV module is directly dependent on the spectrum of the incident radiation and the spectral response of the module.

$$
I_{s c}=\int S R(\lambda) G_{t o t}(\lambda) d \lambda
$$

where $\operatorname{SR}(\lambda)$ is the spectral response of the module and $G_{\text {tot }}(\lambda)$ is the combination of all sources of irradiation on the surface of the module. Therefore, in order to define the effective albedo, it is useful to define the albedo of a material as the ratio of $\mathrm{I}_{\mathrm{sc}}$ developed due to albedo irradiation to the $\mathrm{I}_{\mathrm{sc}}$ developed from all other sources of irradiation, as shown in [10], which define a spectrally responsive albedo $\left(\alpha_{\mathrm{SR}}\right)$ as:

$$
\alpha_{S R}=\frac{\int A(\lambda) S R(\lambda) G_{t o t}(\lambda) d \lambda}{\int S R(\lambda) G_{t o t}(\lambda) d \lambda}
$$

In order to calculate the effective albedo for a given surface/PV material combination, reflectance data for the surface materials, and EQE/SR data for the PV materials, was necessary. By looking at changes in $\left(\alpha_{\mathrm{SR}}\right)$ it is possible to observe how the combined effects of surface reflectance and PV materials can impact system output.

\subsection{Selection of PV materials}

Seven PV materials were selected from recently tested commercial solar cells published in $[18,19]: 1$ ) crystalline silicon (c-Si, UNSW), 2) multicrystalline silicon (mc-Si, Q-cells), 3) hydrogenated amorphous silicon based (a-Si:H, Oerliken Solar Lab), 4) cadmium telluride (CdTe, PrimeStar), 5) copper zinc tin selenium (CZTSS, IBM), 6) gallium aresenide (GaAs, Alta Devices) and 7) organic PV (Solarmer). The EQE of c-Si, a-Si:H, and organic technologies was obtained from version 36 of the solar efficiency tables by Green, Emery, Hishikawa, and Warta [19] and EQE data for the mc-Si, CdTe, CZTSS, and GaAs technologies was obtained from version 38 of the solar efficiency tables by Green, 
Published: M.P. Brennan, A.L. Abramase, R.W. Andrews, J. M. Pearce, Effects of spectral albedo on solar photovoltaic devices, Solar Energy Materials and Solar Cells, 124, pp. 111-116,(2014). DOI: http://dx.doi.org/10.1016/j.solmat.2014.01.046.

Emery, Hishikawa, Warta, and Dunlop [18]. The normalized external quantum efficiencies (EQE) of the seven PV materials are shown in Figure 1.

These materials represent a range of both well-established commercial single junction devices (such as the poli- and mono-crystalline silicon cells) and next generation devices. It can be seen that the thin film devices typically have narrower quantum efficiency which makes them potentially more sensitive to spectral fluctuations.

The relationship between the EQE in Figure 1 and the spectral response is given by:

$$
S R(\lambda)=\frac{e \lambda(E Q E)}{h c}
$$

where $\lambda$ is the wavelength, $h$ is Plank's constant, $c$ is the speed of light and e is the elementary charge $\left(1.6 \times 10^{-19} \mathrm{C}\right)$.

\subsection{Selection of surface materials}

The twenty-two surface materials chosen were divided into three categories based on likely application and can be seen summarized in Table 1. Table 1 lists materials that are likely to occur in proximity to a PV system in industrial, commercial and residential settings. In the commercial and residential categories the materials are primarily those of common roofing materials or materials likely to occur on adjacent walls. In the industrial category the materials are ground surface materials. Table 1 also summarizes the seven types of PV materials evaluated. Reflectance data for the chosen surface materials was obtained from the ASTER Spectral Library provided by the NASA Jet Propulsion Laboratory [20]. This data represents the spectral reflectivity, $A(\lambda)$.

The albedos of the selected materials for each class of PV installation are shown in Figure 1, 2 and 3 for industrial, commercial and residential applications respectively.

\subsection{Solar spectrum generation and calculations}

To obtain the in-plane radiation, $G(\lambda)$, for the calculation of $G_{S R}$ and $A_{S R}$ using a spectrum was generated by the atmospheric modeling program SBDART [21]. The generated spectrum is the same as was used in the analysis by [10], and represents a typical spectrum for mid day on a sunny day at midlatitudes. The data for $\mathrm{A}(\lambda)$ and $\operatorname{SR}(\lambda)$ was interpolated to find the corresponding values of $\mathrm{A}(\lambda)$ and $\operatorname{SR}(\lambda)$ at the wavelengths of the irradiation spectrum data, $G(\lambda)$. The values of $A(\lambda), \operatorname{SR}(\lambda)$, and $G(\lambda)$ were convoluted and integrated using a trapezoidal method over the wavelength range of the spectrum and were normalized by the convoluted and integrated values of $G(\lambda)$ and SR( $\lambda)$ giving a value for $\alpha_{\text {SR. }}$. This was repeated for each combination of surface material and PV material.

\section{Results and Discussion}

The effective albedo was calculated for all of the combinations of surface and PV materials. The results of these calculations can be seen in Figures 5-7 for surface materials which are seen in industrial 
Published: M.P. Brennan, A.L. Abramase, R.W. Andrews, J. M. Pearce, Effects of spectral albedo on solar photovoltaic devices, Solar Energy Materials and Solar Cells, 124, pp. 111-116,(2014). DOI: http://dx.doi.org/10.1016/j.solmat.2014.01.046.

commercial, and residential installations, respectively.

As can be seen in Figure 5 it is interesting to note that for all cases excluding snow, a-Si:H performs poorly, but when combined with snow it out-performs the other PV material technologies investigated and the organic cell was a close second. This is because snow is highly reflective in the UV, as can be seen in Figure 1 and both a-Si:H and the organic cell have narrow EQE with poor spectral response in the infra-red (as can be seen in Figure 1). The band gap of a-Si:H is approximately $1.7 \mathrm{eV}$ which corresponds to a useful spectral range of 300nm-780 nm [17], hence the reflection of light by snow at short wavelengths boosts the efficiency of a-Si materials. Thus for some applications in snowy climates a-Si:H may be a better option [10] It should also be noted for dry grass, whose albedo peaks around $1300 \mathrm{~nm}(\sim 0.95 \mathrm{eV})$ there is a large difference in the performance of the different technologies due to their bandgaps, and as might be predicted, both the organic and a-Si:H materials perform relatively poorly. With their superior response in the infra-red, the mc-Si and c-Si cells perform the best for dry grass surfaces.

Figure 6 shows that the spectral albedo also plays a significant role for commercial rooftops. For example, whereas GaAs and the two crystalline-based Si PV materials have nearly identical low effective albedos for asphalt and black rubber, the crystalline based Si PV materials have a 50\% boost in effective albedo over GaAs near with respect to the albedo of green paint. In addition, a-Si:H was the highest performer for galvanized steel, but was again the lowest for all other materials.

In Figure 7, it is seen that the albedo of paint, wood, and brick produce a large difference between the PV technologies, based primarily on their colors. The green paint reflects preferentially after the green portion of the visible spectrum, and thus there is a $143 \%$ increase in the effective albedo between aSi:H and the crystalline based PV technologies. Similarly, there is a $40 \%$ increase in effective albedo between the same two PV materials for the pine wood surface.

These results are useful for system designers, as it provides a realistic estimate of the actual environmental albedo in a region. The $\alpha_{\mathrm{SR}}$ values can be used in lieu of traditional albedo estimations, which are not responsive to the spectral characteristics of the reflecting material and PV device. Because of the large differences in albedo seen from some device/materials combinations, the use of the $\alpha_{S R}$ may affect system optimizations, and could allow a system designer to take greater advantage of the reflected albedo resource.

This line of analysis can be expanded for future work to investigate i) effects on the optimization of bifacial modules, ii) to optimize PV located near bodies of water so that the albedo from surface water in various weather conditions can be accounted for in system design, iii) multijunction cells and the optimization of multijunction cell design for location (geographic) and local environments, which could lead towards cells rated for specific geographic locations. This could potentially lead to the decommodification of PV modules by enabling geographic optimization for the micro-environment. If the spectrum of a specific location is known (such as with open source repositories of spectral measurements and module performance as with the Open Source Outdoors Test Field [22]), modules can be selected and optimized to be a best match with the prevailing atmospheric conditions at a site. This is especially interesting with the introduction of III-V multijunction devices, which will have a 
Published: M.P. Brennan, A.L. Abramase, R.W. Andrews, J. M. Pearce, Effects of spectral albedo on solar photovoltaic devices, Solar Energy Materials and Solar Cells, 124, pp. 111-116,(2014). DOI: http://dx.doi.org/10.1016/j.solmat.2014.01.046.

greater sensitivity to the atmospheric spectrum due to the ability to tune the bandgap of certain materials for multijunction PV devices. Finally, it can provide insight into the optimal development of potential future dynamic bandgap materials.

\section{Conclusions}

This paper provided analysis of the effects of spectral biasing due to the albedo of commonly occurring surfaces in industrial, commercial and residential PV applications by providing effective albedos for twenty-two commonly occurring surface materials and seven PV materials. The results enable PV system installers to optimize the selection of PV materials for specific environment. This can potentially lead to the decommodification of PV modules by enabling geographic optimization for the micro-environment. In addition, the results assist both the planning or future or existing surface selection for materials in the vicinity of PV arrays to increase output from albedo related energy.

\section{References}

[1] J. Pearce, Photovoltaics - A Path to Sustainable Futures, Futures 34(7) (2002) 663-674.

[2] J. B. Smith, S. H. Schneider, M. Oppenheimer, G. W. Yohe, W. Hare, M. D. Mastrandrea, ... J. P. Van Ypersele, Assessing dangerous climate change through an update of the Intergovernmental Panel on Climate Change (IPCC) "reasons for concern". Proceedings of the National Academy of Sciences, 106(11) (2009) 4133-4137.

[3] A. J. McMichael, R. E.Woodruff, S. Hales, Climate change and human health: present and future risks. The Lancet, 367(9513) (2006) 859-869.

[4] N. Stern, The Economics of Climate Change: The Stern Review, Cambridge University Press: Cambridge, UK, 2007.

[5] Intergovernmental Panel on Climate Change. Climate Change 2007: Synthesis Report. Intergovernmental Panel on Climate Change; Cambridge University Press: Cambridge, UK, 2008. [6] K. Branker, M. J.M. Pathak, J. M. Pearce, A Review of Solar Photovoltaic Levelized Cost of Electricity, Renewable \& Sustainable Energy Reviews 15, (2011) 4470-4482.

[7] R. Kenny, C. Law, J.M. Pearce, Towards Real Energy Economics: Energy Policy Driven by LifeCycle Carbon Emission, Energy Policy 38 (2010) 1969-1978.

[8] R. E. Smalley, Future global energy prosperity: the terawatt challenge, MRS Bull. 30(6) (2005) 412-417.

[9] K. Zweibel, The terawatt challenge for thin-film PV. National Renewable Energy Laboratory (2005).

[10] R. W. Andrews, J. M. Pearce, The Effect of Spectral Albedo on Amorphous Silicon and Crystalline Silicon Solar Photovoltaic Device Performance, Solar Energy 91 (2013) 233-241.

[11] M. M. D. Ross, Snow and Ice Accumulation on Photovoltaic Arrays: An Assessment of the TN Conseil Passive Melting Technology, Report\# EDRL 95-68 (TR), Energy Diversification Research Laboratory, CANMET, Natural Resources Canada, Varennes, September, 1995.

[12] N. Kasahara, K. Yoshioka, T. Saitoh, Performance evaluation of bifacial photovoltaic modules for urban application, Proc. of 3rd World Conf. on Photovoltaic Energy Conversion, 3(2) (2003) 24552458. 
Published: M.P. Brennan, A.L. Abramase, R.W. Andrews, J. M. Pearce, Effects of spectral albedo on solar photovoltaic devices, Solar Energy Materials and Solar Cells, 124, pp. 111-116,(2014). DOI: http://dx.doi.org/10.1016/j.solmat.2014.01.046.

[13] ASTM, G173-03(2008) Standard tables for reference solar spectral irradiances: Direct normal and hemispherical on 37 tilted surface (2008).

[14] R. Rther, J. Livingstone, Seasonal variations in amorphous silicon solar module outputs and thin film characteristics, Solar Energy Materials and Solar Cells 36 (1995) 29-43.

[15] R. Rther, G. Kleiss, K. Reiche, Spectral effects on amorphous silicon solar module fill factors, Solar Energy Materials and Solar Cells 71 (2002) 375-385.

[16] R. Gottschalg, Experimental study of variations of the solar spectrum of relevance to thin film solar cells, Solar Energy Materials and Solar Cells 79 (2003) 527-537.

[17] R. Gottschalg, T.R. Betts, D.G. Infield, M.J. Kearney, On the importance of considering the incident spectrum when measuring the outdoor performance of amorphous silicon photovoltaic devices, Measurement Science and Technology 15 (2004) 460-466.

[18] M.A. Green, K. Emery, Y. Hishikawa, W.Warta, E. D. Dunlop, Solar Cell Efficiency Tables (version 38), Progress in Photovoltaics: Research and Applications 19(5) (2011) 565-572.

[19] M.A. Green, K. Emery, Y. Hishikawa, W.Warta, Solar Cell Efficiency Tables (version 36), Progress in Photovoltaics: Research and Applications 18(5) (2010) 346-352.

[20] A. Baldridge, S. Hook, C. Grove, G. Rivera, The ASTER spectral library version 2.0, Remote Sensing of Environment 113 (2009) 711-715.

[21] Ricchiazzi, Paul, Shiren Yang, Catherine Gautier, David Sowle, 1998: SBDART: A Research and Teaching Software Tool for Plane-Parallel Radiative Transfer in the Earth's Atmosphere. Bull. Amer. Meteor. Soc., 79, 2101-2114.

[22] J.M. Pearce, A. Babasola, R. Andrews, Open Solar Photovoltaic Systems Optimization, Proceedings of the 16th Annual National Collegiate Inventors and Innovators Alliance Conference, Open (2012) 1-7. 


\section{Figure Captions}

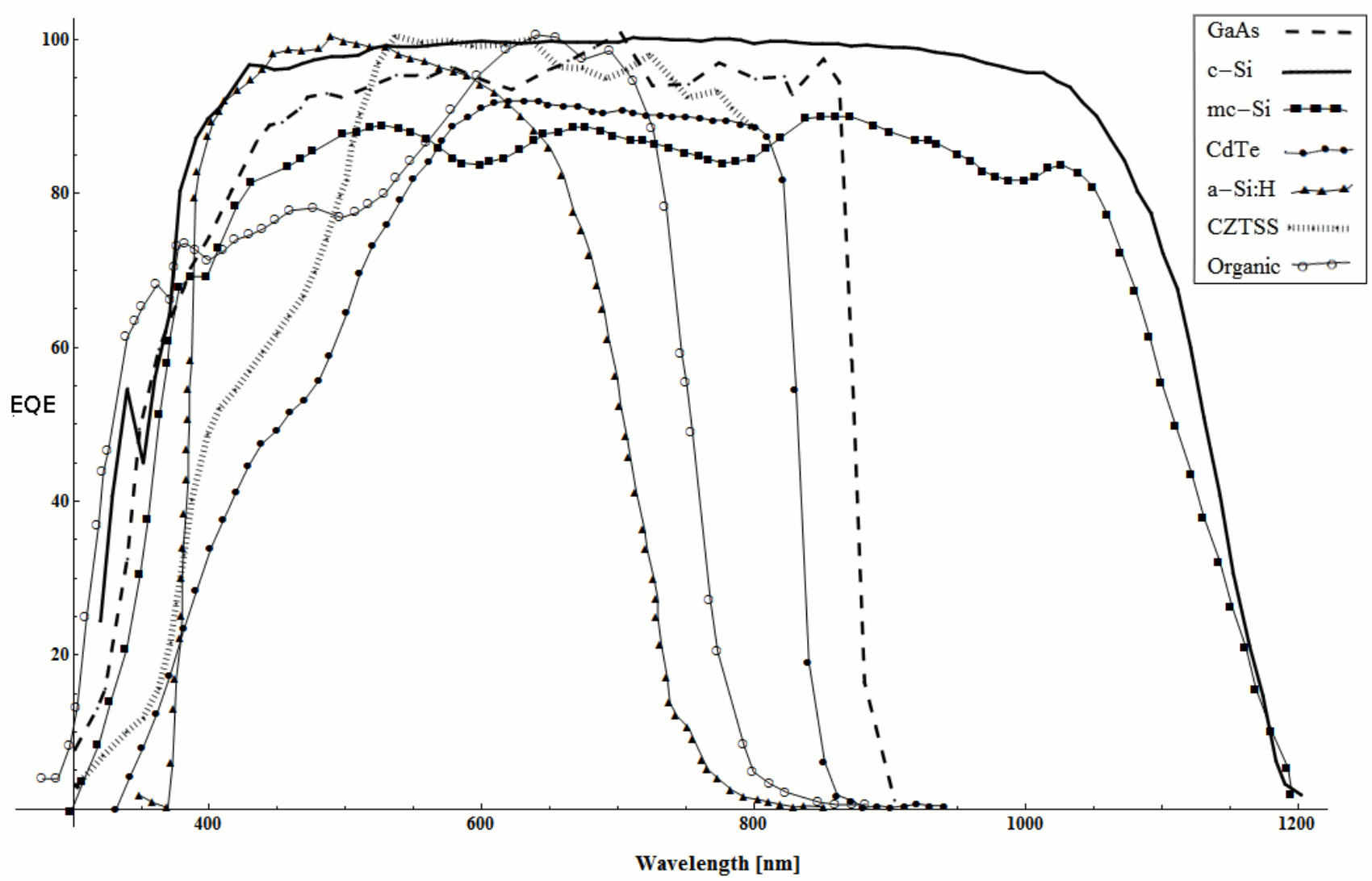

Figure 1. The normalized EQE of the seven PV materials: 1) crystalline silicon (c-Si), 2) multicrystalline silicon (mc-Si), 3) hydrogenated amorphous silicon based (a-Si:H), 4) cadmium telluride (CdTe), 5) (CZTSS), 6)gallium aresenide (GaAs) and 7) organic PV. 
Published: M.P. Brennan, A.L. Abramase, R.W. Andrews, J. M. Pearce, Effects of spectral albedo on solar photovoltaic devices, Solar Energy Materials and Solar Cells, 124, pp. 111-116,(2014). DOI: http://dx.doi.org/10.1016/j.solmat.2014.01.046.

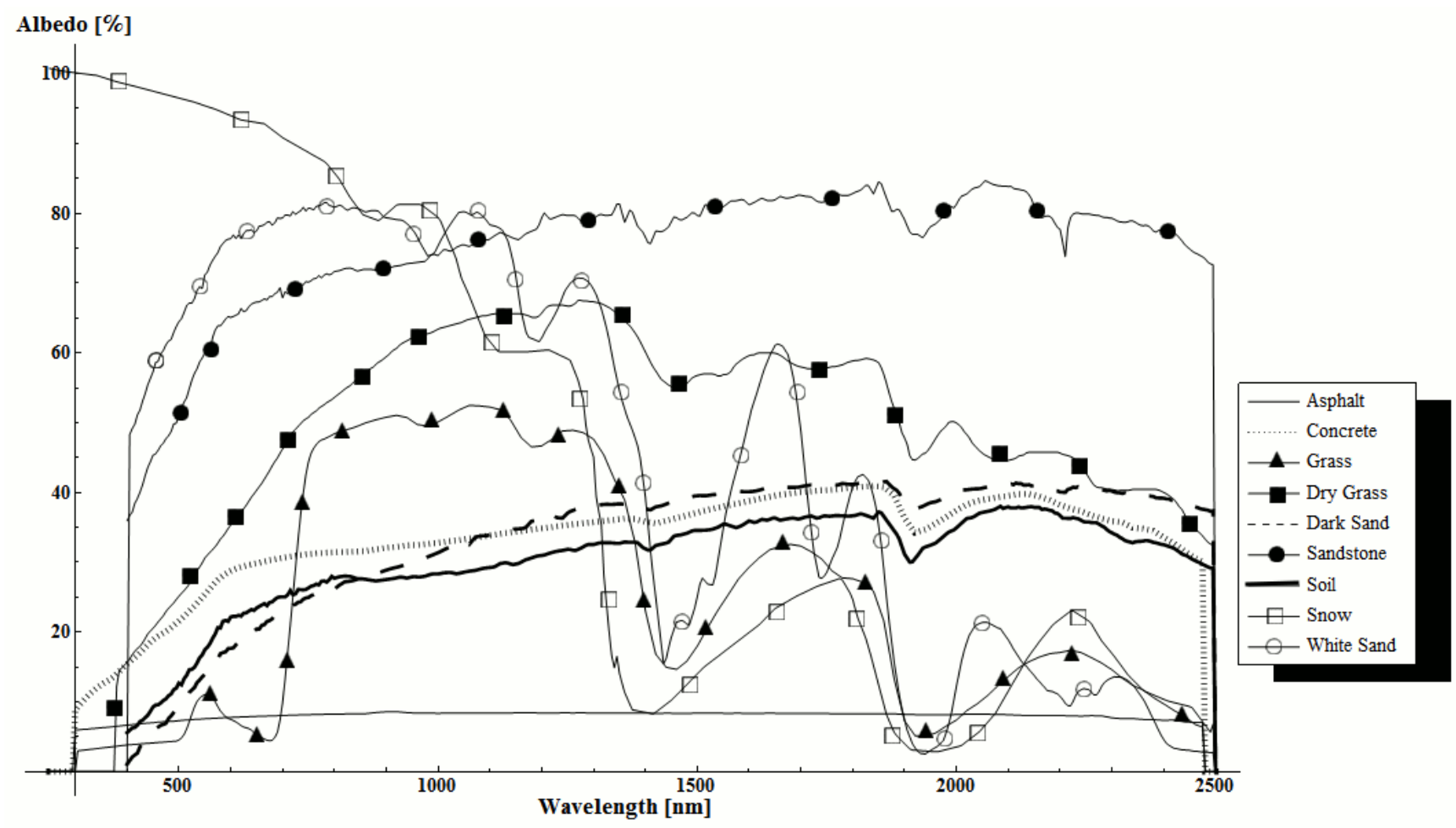

Figure 2. The albedo spectrum for the selected materials for industrial (solar farm) PV applications.

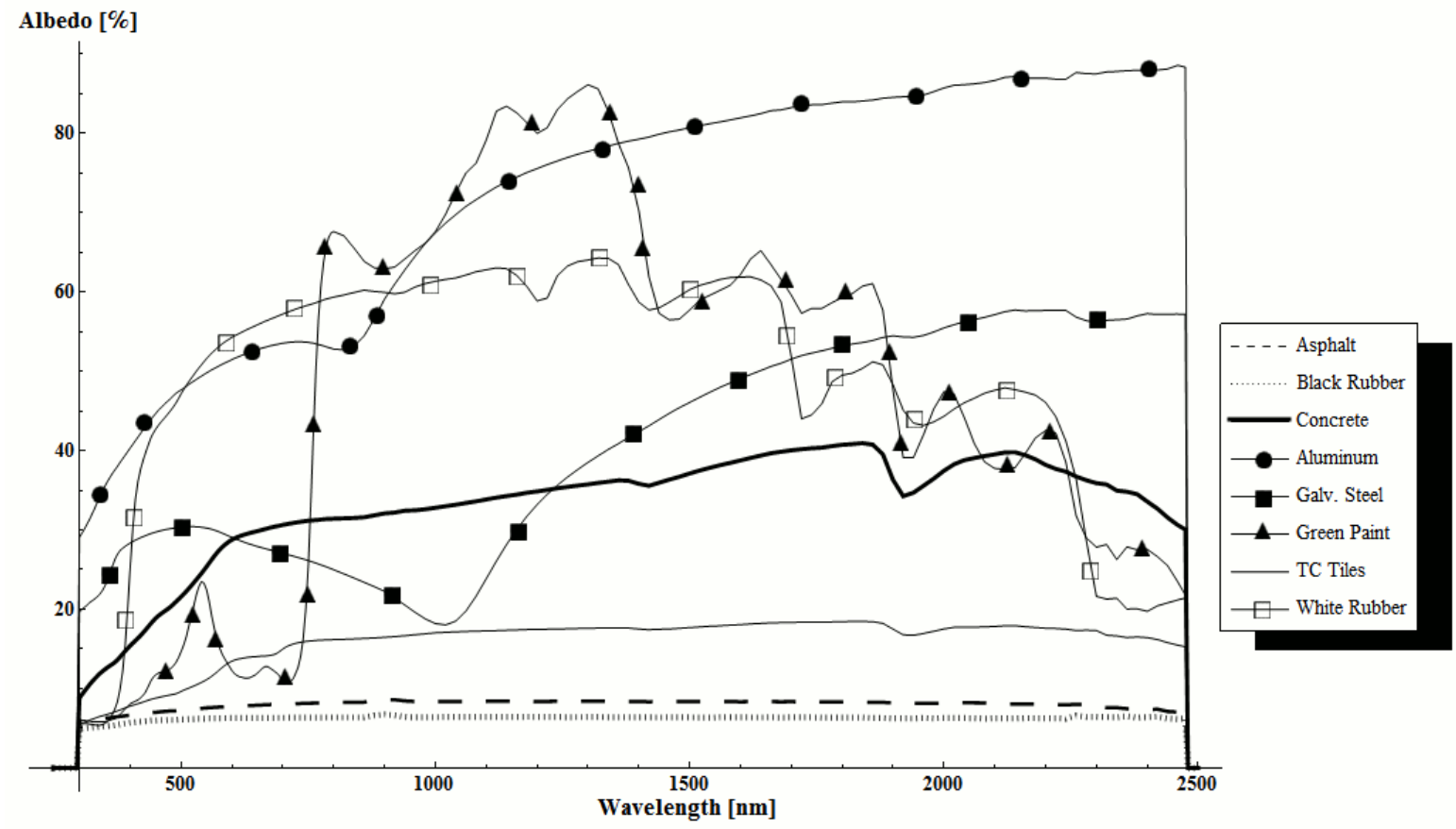

Figure 3. The albedo spectrum for the selected materials for commercial rooftop PV applications. 
Published: M.P. Brennan, A.L. Abramase, R.W. Andrews, J. M. Pearce, Effects of spectral albedo on solar photovoltaic devices, Solar Energy Materials and Solar Cells, 124, pp. 111-116,(2014). DOI: http://dx.doi.org/10.1016/j.solmat.2014.01.046.

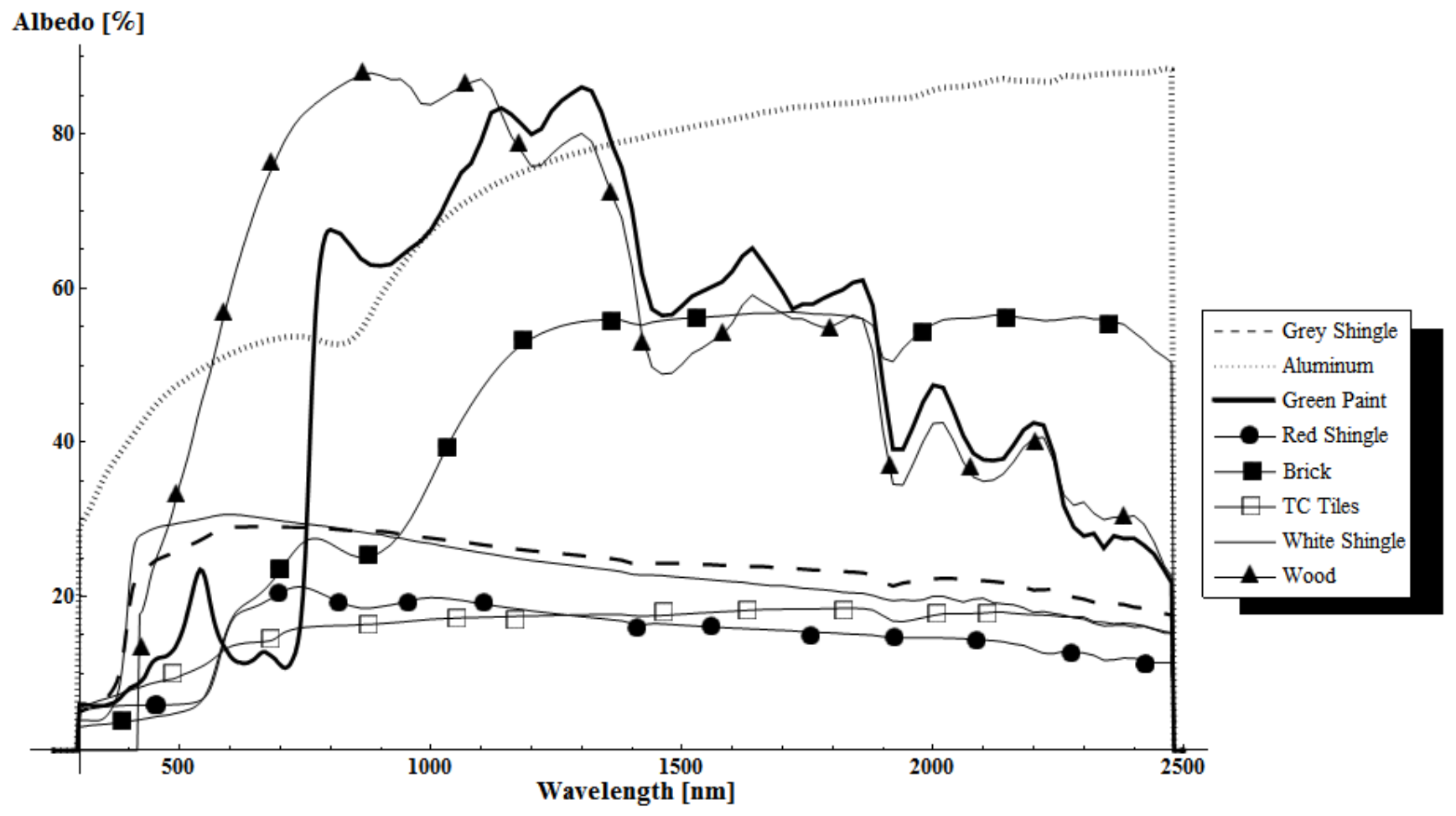

Figure 4. The albedo spectrum for the selected materials for residential rooftop PV applications. 
Published: M.P. Brennan, A.L. Abramase, R.W. Andrews, J. M. Pearce, Effects of spectral albedo on solar photovoltaic devices, Solar Energy Materials and Solar Cells, 124, pp. 111-116,(2014). DOI: http://dx.doi.org/10.1016/j.solmat.2014.01.046.

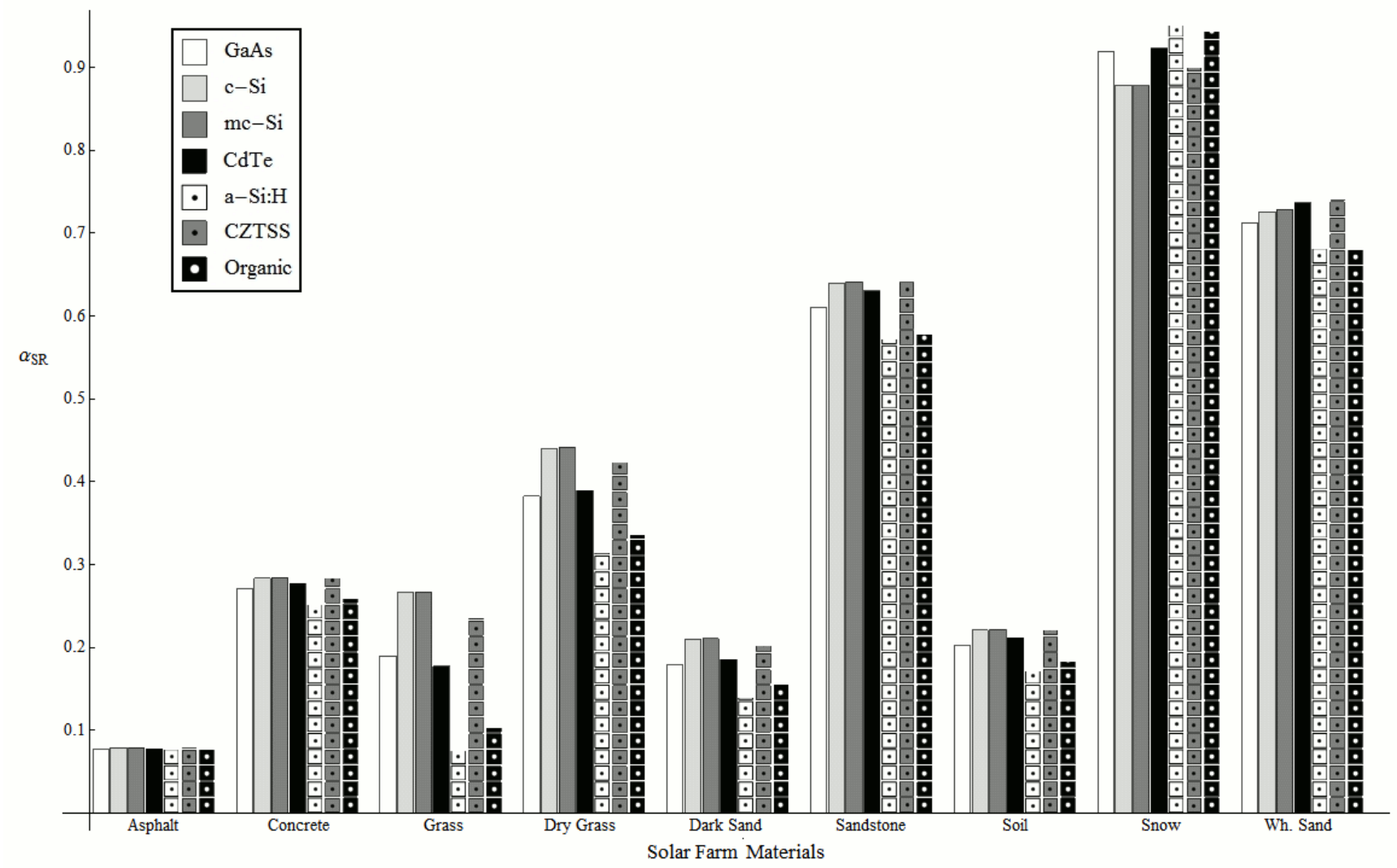

Figure 5. Effective albedo as calculated using various PV technologies for surface materials typically encountered in an industrial (solar farm) environment. 
Published: M.P. Brennan, A.L. Abramase, R.W. Andrews, J. M. Pearce, Effects of spectral albedo on solar photovoltaic devices, Solar Energy Materials and Solar Cells, 124, pp. 111-116,(2014). DOI: http://dx.doi.org/10.1016/j.solmat.2014.01.046.

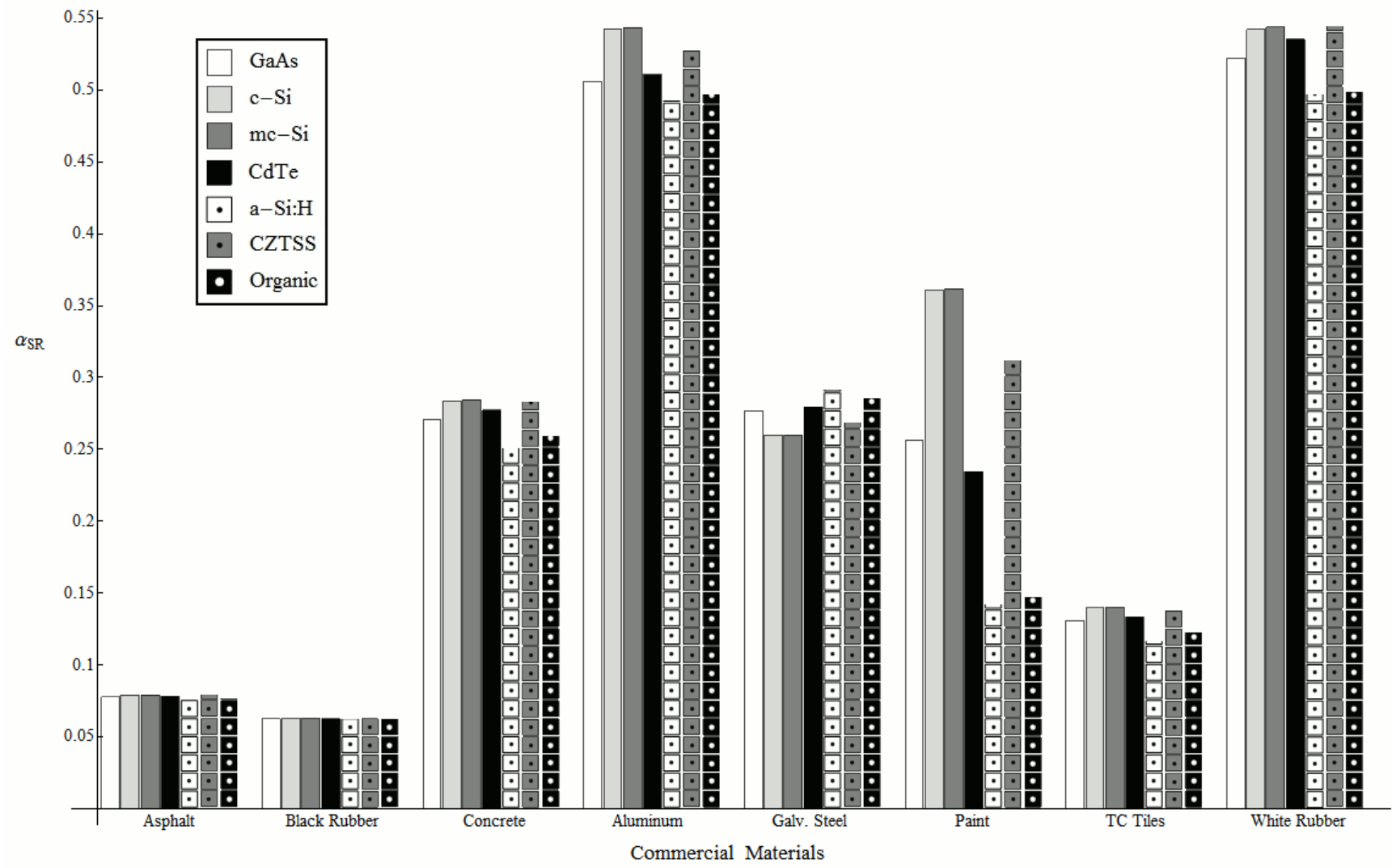

Figure 6. Effective albedo as calculated using various PV technologies for surface materials typically encountered in commercial use. 
Published: M.P. Brennan, A.L. Abramase, R.W. Andrews, J. M. Pearce, Effects of spectral albedo on solar photovoltaic devices, Solar Energy Materials and Solar Cells, 124, pp. 111-116,(2014). DOI: http://dx.doi.org/10.1016/j.solmat.2014.01.046.

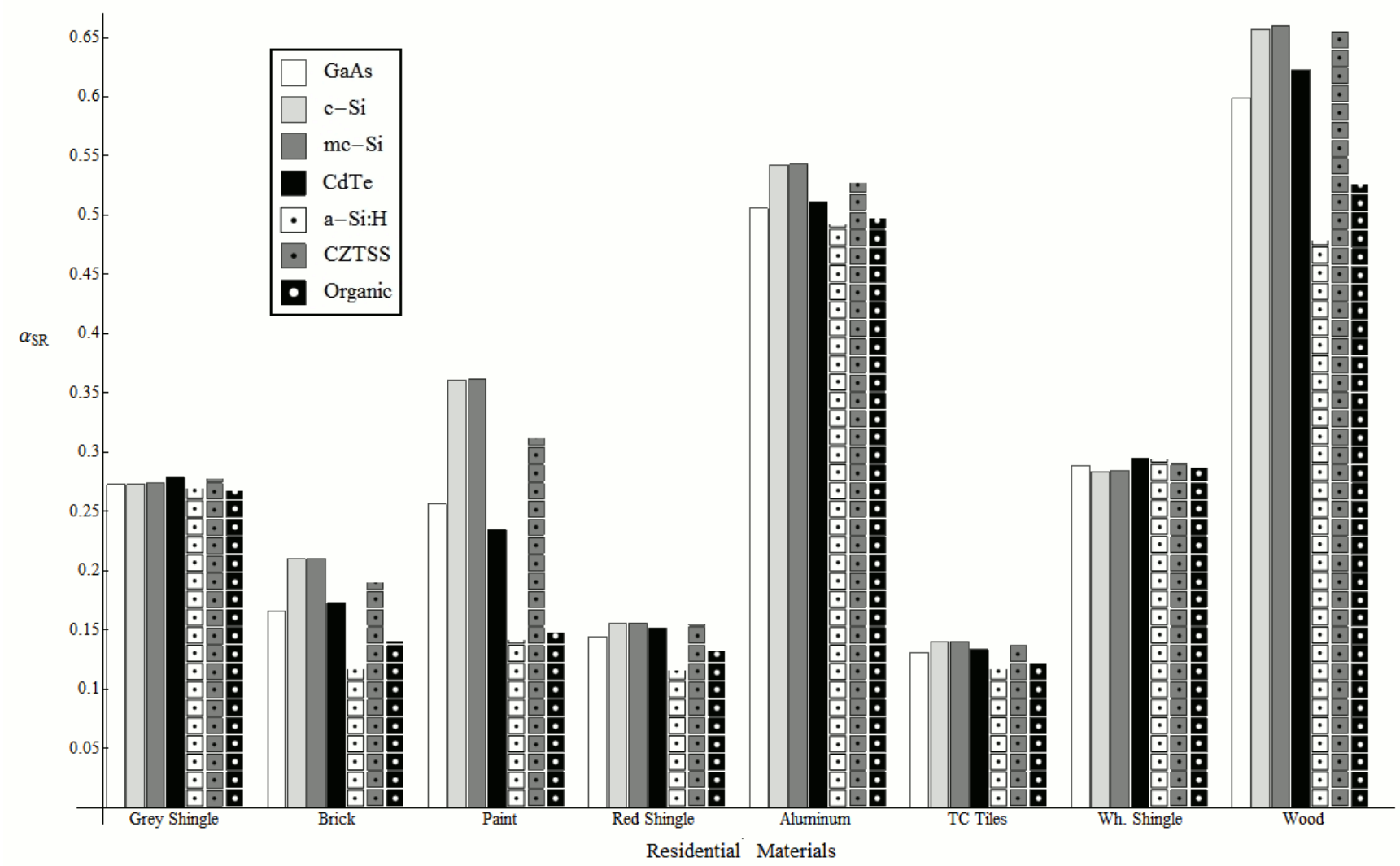

Figure 7. Effective albedo as calculated using various PV technologies for surface materials typically encountered in residential use. 